\title{
Relation between QT and RR intervals in patients with bradyarrhythmias
}

\author{
Shuji Ishida, Naohiko Takahashi, Mikiko Nakagawa, Takao Fujino, Tetsunori Saikawa, \\ Morio Ito
}

\begin{abstract}
Objective-To investigate the relation between $Q T$ and $R R$ intervals in the sick sinus syndrome or high degree atrioventricular block.

Patients-32 patients with episodes of prolonged $R R$ intervals $(\geqslant 2.6 \mathrm{~s})$ on Holter electrocardiographic recordings. Design-QT and RR intervals were measured manually every 100 to 150 beats on electrocardiographic strips reprinted from the Holter tape over 24 hours. The slope of the QT/RR relation was determined by the linear regression equation for $R R$ intervals $\leqslant 1.4 \mathrm{~s}$ (slope 1) and $>1 \cdot 4$ s (slope 2).

Results-Slope $2(0.0068(0.0030))$ was significantly lower than slope $1(0.0824$ $(0.0059), P<0.0001)$ in the overall patient population. Slopes 1 and 2 were significantly lower $(P<0.001)$ in the 23 patients with $Q T$ intervals at the preceding $R R$ interval of $1 \mathrm{~s}\left(\mathrm{QT}_{1 \mathrm{~s}}\right)$ of $<0.44 \mathrm{~s}(0.0692$ $(0.0053)$ and $0.0019(0.0030)$, respectively) than in the nine patients with $\mathbf{Q T}_{1 \mathrm{~s}}$ intervals $\geqslant 0.44 \mathrm{~s}(0.1159(0.0091)$ and 0.0194 $(0 \cdot 0055)$, respectively). Slopes 1 and 2 correlated positively with $\mathbf{Q T}_{1 \mathrm{~s}}$ interval in all patients.

Conclusions-The QT/RR relation was comparatively flat when the RR interval was prolonged. Patients with prolonged QT intervals showed exaggerated prolongation of the QT interval with prolonged cycle lengths when compared with patients with normal QT intervals.
\end{abstract}

(Br Heart f 1995;74:159-162)

Keywords: QT interval; RR interval; sick sinus syndrome; atrioventricular block

Laboratory Medicine,

Oita Medical

University, Oita,

Japan

$S$ Ishida

N Takahashi

M Nakagawa

T Fujino

M Ito

Department of Internal Medicine,

Oita Medical

University, Oita,

Japan

T Saikawa

Correspondence to:

Dr S Ishida, Department of

Laboratory Medicine, Oita

Medical University,

Hasama-machi 1-1, Oita

879-55, Japan.

Accepted for publication

16 January 1995 physiological bradycardia. We investigated the relation between $Q T$ and $R R$ intervals in patients with episodes of bradycardia due to the sick sinus syndrome or atrioventricular block.

\section{Patients and methods}

We analysed 24 hour ambulatory electrocardiographic recordings obtained in 32 consecutive patients ( 15 men and 17 women, mean age $58.4(3.3)$ years) with the sick sinus syndrome (25 patients) or atrioventricular block (seven). All patients had episodes of prolonged RR intervals $\geqslant 2.6 \mathrm{~s}$ on 24 hour electrocardiographic recordings. Three patients were receiving class I antiarrhythmic agents. Patients with angina pectoris, myocardial infarction, valvar heart disease, congestive heart failure, myocardial disease, the WolffParkinson-White syndrome, bundle branch block, or artificial pacemakers were excluded from the study.

Twenty four hour electrocardiographic recordings were performed with a two channel Marquette series 8000 recorder and were analysed with a Marquette 8000 scanner. QRST complexes at preceding RR intervals, identified on $R R$ interval histograms, were replayed at random from either lead 1 (right manubrial border of the sternum and the sixth rib at the left anterior axillary line) or lead 2 (left manubrial border of the sternum and 2 $\mathrm{cm}$ right of xiphoid process on the rib margin) and printed at a paper speed of $25 \mathrm{~mm} / \mathrm{s}$. Original recordings were magnified to $200 \%$ with a photocopier. The QT intervals were measured manually for every 100 to 150 beats by two cardiologists who were unaware of the patients' clinical characteristics. Their results were averaged. The end point of the $T$ wave was defined as the intersection of the steepest slope of the descending $T$ wave and the baseline. The QT interval was plotted against the preceding $R R$ interval. At the preceding $R R$ interval of $1 \mathrm{~s}$ at least five QT intervals at random time were measured and averaged as the QT interval at $R R$ interval of $1 \mathrm{~s}\left(\mathrm{QT}_{1 \mathrm{~s}}\right)$. An abnormal QT prolongation was defined as a $\mathrm{QT}_{1 \mathrm{~s}}$ interval of $0.44 \mathrm{~s}$ or longer. ${ }^{89}$ Patients were divided into two groups according to whether their $\mathrm{QT}_{1 \mathrm{~s}}$ interval was $<0.44 \mathrm{~s}(23$ patients, group A) or $\geqslant 0.44 \mathrm{~s}$ (nine patients, group B) (table 1). The presence or absence of ventricular tachycardia (three or more consecutive ventricular ectopic beats at a rate $>100 / \mathrm{min}$ ) was also determined over 24 hours.

Data are expressed as means (SE), unless specified otherwise. Statistical analysis was performed using the Student's $t$ test or $\chi^{2}$ test when appropriate. Standard linear regression methods were used to calculate the slope of the $Q T / R R$ relation (QT/RR slope) for $R R$ intervals $\leqslant 1.4 \mathrm{~s}$ (slope 1 ) and $>1.4 \mathrm{~s}$ (slope 2). $\mathrm{P}<0.05$ was accepted as significant. 
Table 1 Clinical characteristics and electrocardiographic findings in 32 patients

\begin{tabular}{|c|c|c|c|c|c|c|}
\hline Case No & Age & Sex & Diagnosis & Drugs taken & Ventricular tachycardia & $Q T_{\text {Is }}(s)$ \\
\hline \multicolumn{7}{|c|}{ Group $A$} \\
\hline 1 & 61 & $\mathrm{~F}$ & Sick sinus syndrome & & No & 0.43 \\
\hline 2 & 32 & $\mathbf{M}$ & Sick sinus syndrome & Procainamide & Yes & 0.34 \\
\hline 3 & 78 & $\mathrm{~F}$ & Sick sinus syndrome & \multirow[t]{5}{*}{ Theophylline } & No & $0 \cdot 38$ \\
\hline 4 & 71 & $\mathrm{~F}$ & Sick sinus syndrome & & No & 0.43 \\
\hline 5 & 69 & $\mathbf{M}$ & Sick sinus syndrome & & No & 0.42 \\
\hline 6 & 15 & $\mathbf{M}$ & Atrioventricular block & & No & 0.35 \\
\hline 7 & 67 & $\mathrm{~F}$ & Sick sinus syndrome & & No & 0.41 \\
\hline 8 & 64 & M & Sick sinus syndrome & \multirow[t]{3}{*}{ Mexiletine } & Yes & 0.37 \\
\hline 9 & 70 & $\mathbf{M}$ & Sick sinus syndrome & & No & $0 \cdot 38$ \\
\hline 10 & 49 & $\mathrm{~F}$ & Sick sinus syndrome & & No & 0.39 \\
\hline 11 & 70 & $\mathrm{M}$ & Sick sinus syndrome & \multirow[t]{3}{*}{ Procainamide } & No & 0.38 \\
\hline 12 & 60 & $\mathrm{~F}$ & Sick sinus syndrome & & Yes & 0.41 \\
\hline 13 & 35 & $\mathbf{M}$ & Sick sinus syndrome & & Yes & $0 \cdot 40$ \\
\hline 14 & 75 & $\mathrm{~F}$ & Atrioventricular block & \multirow[t]{8}{*}{ Orciprenaline } & No & 0.42 \\
\hline 15 & 48 & $\mathrm{~F}$ & Sick sinus syndrome & & No & 0.41 \\
\hline 16 & 60 & $\mathrm{~F}$ & Sick sinus syndrome & & No & 0.41 \\
\hline 17 & 15 & $\mathbf{M}$ & Atrioventricular block & & No & 0.39 \\
\hline 18 & 66 & $\mathbf{M}$ & Atrioventricular block & & No & 0.42 \\
\hline 19 & 58 & $\mathrm{~F}$ & Sick sinus syndrome & & No & 0.35 \\
\hline 20 & 67 & $\mathbf{M}$ & Atrioventricular block & & Yes & $0 \cdot 40$ \\
\hline 21 & 61 & $\mathbf{M}$ & Sick sinus syndrome & & No & 0.40 \\
\hline 22 & 58 & $\mathbf{M}$ & Sick sinus syndrome & \multirow[t]{2}{*}{ Orciprenaline } & No & 0.42 \\
\hline 23 & 42 & $\mathbf{M}$ & Sick sinus syndrome & & No & $0 \cdot 39$ \\
\hline & & & & \multicolumn{3}{|c|}{ Group B } \\
\hline $\begin{array}{l}24 \\
25\end{array}$ & $\begin{array}{l}76 \\
74\end{array}$ & $\begin{array}{l}\mathrm{F} \\
\mathrm{M}\end{array}$ & $\begin{array}{l}\text { Sick sinus syndrome } \\
\text { Sick sinus syndrome }\end{array}$ & \multirow{8}{*}{ Orciprenaline } & $\begin{array}{l}\text { No } \\
\text { No }\end{array}$ & $\begin{array}{l}0 \cdot 44 \\
0.44\end{array}$ \\
\hline $\begin{array}{l}25 \\
26\end{array}$ & 76 & $\mathrm{~F}$ & $\begin{array}{l}\text { Sick sinus syndrome } \\
\text { Atrioventricular block }\end{array}$ & & $\begin{array}{l}\text { No } \\
\text { Yes }\end{array}$ & $\begin{array}{l}0.44 \\
0.54\end{array}$ \\
\hline 27 & 78 & $\mathbf{F}$ & Sick sinus syndrome & & No & 0.68 \\
\hline 28 & 84 & $\mathrm{~F}$ & Sick sinus syndrome & & No & 0.47 \\
\hline 29 & 61 & $\mathrm{~F}$ & Sick sinus syndrome & & No & 0.44 \\
\hline 30 & 46 & $\mathrm{~F}$ & Sick sinus syndrome & & No & 0.46 \\
\hline 31 & 16 & $\mathbf{M}$ & Atrioventricular block & & No & 0.45 \\
\hline 32 & 67 & F & Sick sinus syndrome & & Yes & 0.47 \\
\hline
\end{tabular}

$\mathrm{QT}_{\mathrm{ls}}, \mathrm{QT}$ interval at preceding RR interval of $1 \mathrm{~s}$.

\section{Results}

There were no significant differences in age distribution, sex ratio, the percentage of patients with ventricular tachycardia, mean daily $R R$ interval, or the minimum and maximum RR intervals between patients with normal (group A) and prolonged (group B) $\mathrm{QT}_{1 \mathrm{~s}}$ intervals (table 2). Torsades de pointes was documented in one patient in group B (case 26) several days before the 24 hour electrocardiographic recordings were taken. The QT interval was prolonged linearly when $R R$ intervals were less than $1.4 \mathrm{~s}$ in all patients. However, patients in group A showed a relatively flat $\mathrm{QT} / \mathrm{RR}$ relation curve at longer $\mathrm{RR}$ intervals, whereas in group B the QT interval was prolonged even in the presence of obvious bradycardia (figure 1). Slope 2 was significantly lower than slope 1 in both group $A$ and group B (table 2). Both slope 1 and slope 2 were significantly higher in group $\mathrm{A}$ than in

Table 2 Clinical and electrocardiographic characteristics in patients with normal and prolonged $Q T$ intervals. Values are means (SE) unless stated otherwise

\begin{tabular}{|c|c|c|c|}
\hline & $\begin{array}{l}\text { All patients } \\
(n=32)\end{array}$ & $\begin{array}{l}\text { Group } A \\
(n=23)\end{array}$ & $\begin{array}{l}\text { Group B } \\
(n=9)\end{array}$ \\
\hline Age (years) & $58 \cdot 4(3 \cdot 3)$ & $56 \cdot 1(3 \cdot 7)$ & $64 \cdot 2(7 \cdot 1)$ \\
\hline $\begin{array}{l}\text { No of men/women } \\
\text { No of patients with }\end{array}$ & \multicolumn{2}{|c|}{ No of patients with } & $2 / 7$ \\
\hline SSS/AV block & $25 / 7$ & $18 / 5$ & $7 / 2$ \\
\hline $\begin{array}{l}\mathrm{QT}_{1 \mathrm{~s}}(\mathrm{~s}) \\
\text { No of patients with VT }\end{array}$ & $\begin{array}{l}0.422(0.011) \\
7\end{array}$ & $\begin{array}{l}0.396(0.005) \\
5\end{array}$ & $\begin{array}{l}0 \cdot 488(0 \cdot 026)^{\star \star} \\
2\end{array}$ \\
\hline \multicolumn{4}{|l|}{$\mathrm{RR}$ interval (s): } \\
\hline Mean & $1.04(0.04)$ & $0.99(0.05)$ & $1 \cdot 18(0.08)$ \\
\hline Minimum & $0.57(0.03)$ & $0.54(0.03)$ & $0.64(0.06)$ \\
\hline Maximum & $3.60(0 \cdot 20)$ & $3.54(0.21)$ & $3.78(0.49)$ \\
\hline \multicolumn{4}{|l|}{ QT/RR relation: } \\
\hline Slope 1 & $0.0824(0.0059)$ & $0.0692(0.0053)$ & $0.1159(0.0091)^{\star \star}$ \\
\hline Slope 2 & $0.0068(0.0030)$ & $0.0019(0.0030)$ & $0.0194(0.0055)^{\star}$ \\
\hline
\end{tabular}

AV block, atrioventricular block; $\mathrm{QT}_{\mathrm{ls}}$, QT interval at preceding RR interval of $1 \mathrm{~s}$; SSS, sick sinus syndrome; VT, ventricular tachycardia; slope 1 and slope 2 , slope of the $Q T / R R$ relation at $R R$ interval $\leqslant 1.4 \mathrm{~s}$ and $>1.4 \mathrm{~s}$. ${ }^{\star} \mathrm{P}<0.001$ and ${ }^{\star \star} \mathrm{P}<0.0001 v$ group $\mathrm{A}$. group B. The $\mathrm{QT}_{\mathrm{is}}$ interval correlated positively with both slope 1 and slope 2 in the overall patient population (figure 2).

\section{Discussion}

Heart rate is a major determinant of the QT interval, which becomes short as heart rate
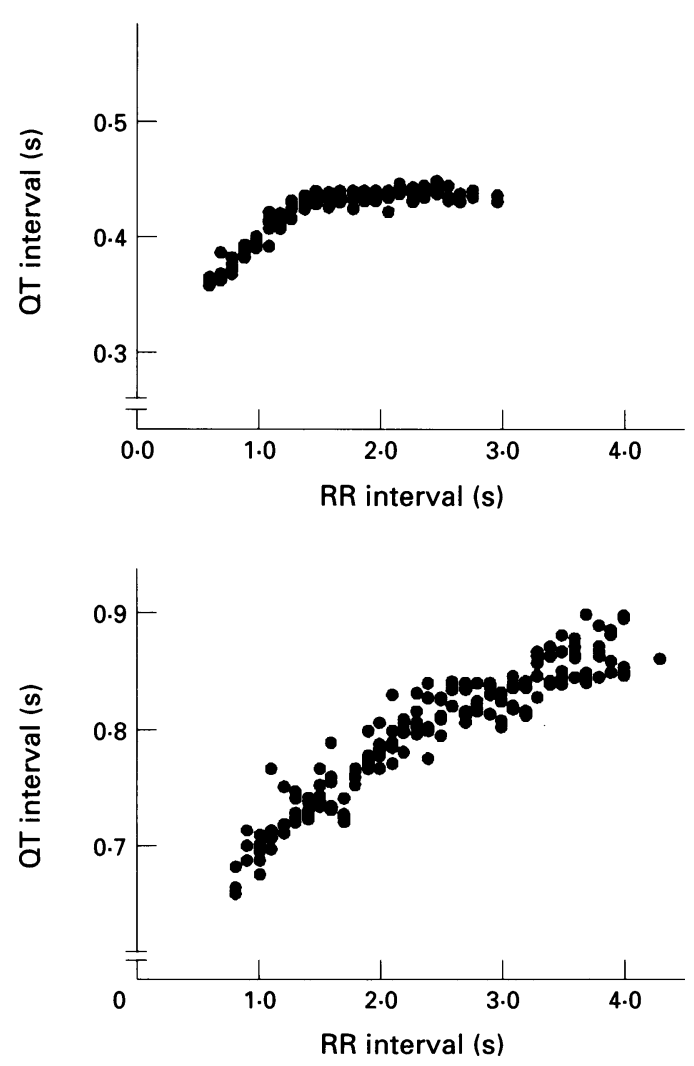

Figure 1 Rate dependent changes in the $Q T$ interval in case 17 (patient with a normal QT interval) (top) and in case 27 (patient with a long QT interval) (bottom). 
Figure 2 Regression plots of the slope of the $Q T / R R$ relation versus the $Q T$ interval at the preceding $R R$ interval of $1 \mathrm{~s}\left(Q T_{1 s}\right)$ Slope 1 applies to the $Q T / R R$ relation for $R R$ intervals $\leqslant 1.4 \mathrm{~s}$ (top) and slope 2 to the relation for $R R$ intervals $>1.4 \mathrm{~s}$ (bottom).
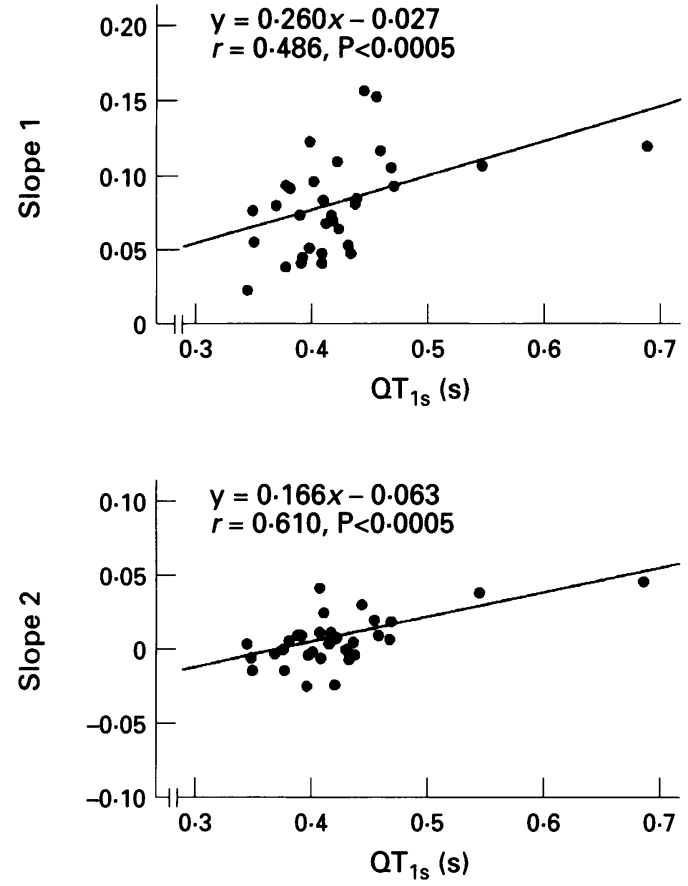

increases. ${ }^{12}$ Most previous studies analysing the $Q T / R R$ relation used heart rates (or RR intervals) in the physiological range. To our knowledge, ours is the first study to examine the response of the QT interval to changes in $R R$ interval well beyond the physiological range.

We found that the QT interval was shortened at shorter $R R$ intervals in patients with sinus node or atrioventricular node dysfunction. Most patients, however, showed a relatively flat $Q T / R R$ relation curve at $R R$ intervals $>1.4 \mathrm{~s}$. Accordingly, we calculated the slope of the QT/RR relation at $R R$ intervals $\leqslant 1.4 \mathrm{~s}$ (slope 1 ) and $>1.4 \mathrm{~s}$ (slope 2) and found that slope 2 was significantly lower than slope 1 in both groups. Sarma et al estimated the $Q T / R R$ relation curve using an exponential formula and found that it tended to flatten out at long RR intervals. ${ }^{10}$ The QT interval is an index of the duration of ventricular repolarisation. ${ }^{1311}$ The duration of the action potential in ventricular and Purkinje fibres is shortened at higher pacing rates, but it shows little change at low pacing rates..$^{12}$

We found that both slope 1 and slope 2 were significantly higher in patients with prolonged $\mathrm{QT}_{1 \mathrm{~s}}$ intervals ( $\geqslant 0.44 \mathrm{~s}$; group $\mathrm{B}$ ) than in those with normal $\mathrm{QT}_{1 \mathrm{~s}}$ intervals (group A) and were positively correlated with the $\mathrm{QT}_{\mathrm{ls}}$ interval. Merri et al measured the interval from the $\mathrm{R}$ wave to the maximum amplitude of the $\mathrm{T}$ wave (RTm) as an index of the duration of ventricular repolarisation and found that the slope of RTm/RR was significantly greater in patients with the long QT syndrome than in normal subjects. ${ }^{13}$ They excluded, however, non-physiological RR intervals (> $2000 \mathrm{~ms}$ ).

The long QT syndrome is associated with malignant ventricular arrhythmias and sudden death. ${ }^{3-5}$ Ventricular tachycardia (often torsades de pointes) is a significant complication of severe bradycardia due to sinus node or atrioventricular node dysfunction and is usually associated with QT prolongation in the presence of bradycardia. ${ }^{367}$ Our findings indicate that patients with prolonged QT intervals at physiological cycle lengths have an exaggerated QT prolongation with prolonged cycle lengths. This phenomenon may explain the occurrence of bradycardia dependent arrhythmic vulnerability in some patients with bradyarrhythmias. $^{367}$

Our study has several limitations. Firstly, the QT interval was measured in only one lead of a 24 hour electrocardiographic recording. If standard 12 lead electrocardiograms had been used, values might have been different.

Secondly, we measured QT and RR intervals every 100-150 beats. If the intervals had been measured for all beats recorded over 24 hours as reported previously, ${ }^{13-15}$ the relation between $Q T$ and $R R$ intervals might have been different.

Thirdly, we ignored the variation in cycle lengths before the measured $R R$ interval. The rate dependency of the duration of ventricular repolarisation is different when heart rate is stable and after an abrupt change. ${ }^{16-18}$

In conclusion, we found that most patients with sinus node or atrioventricular node dysfunction have a flat $Q T / R R$ relation in the presence of marked bradycardia. Compared with patients with a normal QT interval, patients with a long QT interval have an exaggerated QT prolongation with prolonged cycle lengths.

1 Boyett MR, Jewell BR. Analysis of the effect of changes in rate and rhythm upon electrical activity in the heart. Prog Biophys Mol Biol 1980;36:1-52.

2 Ahnve S. Correction of the QT interval for heart rate: review of different formulas and the use of Bazett's formula in myocardial infarction. Am Heart $f 1985 ; 109$ : mula in

3 Jackman WM, Friday KJ, Anderson JL, Aliot EM, Clark $M$, Lazzara $R$. The long QT syndromes: a critical review, new clinical observations and unifying hypothesis. Prog Cardiovasc Dis 1988;31:1 15-72.

4 Schwartz PJ, Wolf S. QT interval prolongation as predictor of sudden death in patients with myocardial infarction. Circulation 1978;57:1074-7.

5 Algra A, Tijssen JGP, Roelandt JRTC, Pool J, Lubsen J. QT interval variables from 24 hour electrocardiography and the two year risk of sudden death. Br Heart $\mathcal{F} 1993$; and the $43-8$.

6 Shimizu W, Tanaka $K$, Suenaga $K$, Wakamoto A. Bradycardia-dependent early afterdepolarizations in a patient with QTU prolongation and torsade de pointes in association with marked bradycardia and hypokalemia. PACE 1991;14:1105-11.

7 Kurita T, Ohe T, Marui N, Aihara N, Takaki H, Kamakura S, et al. Bradycardia-induced abnormal QT prolongation in patients with complete atrioventricular block with torsades de pointes. Am 7 Cardiol 1992;69: 628-33.

8 Bazett HC. An analysis of the time relations of electrocardiograms. Heart 1920;7:353-70.

9 Moss AJ, Schwartz PJ, Crampton RS, Locati E, Carleen E. The long QT syndrome: a prospective international study. Circulation 1985;71:17-21.

10 Sarma JSM, Sarma RJ, Bilitch M, Katz D, Song SL. An exponential formula for heart rate dependence of QT interval during exercise and cardiac pacing in humans: reevaluation of Bazett's formula. Am F Cardiol 1984;54: 103-8.

11 Seed WA, Noble MIM, Oldershaw P, Wanless RB, DrakeHolland AJ, Redwood D, et al. Relation of human cardiac action potential duration to the interval between beats; implications for the validity of rate corrected QT interval (QTc). Br Heart f 1987;57:32-7.

12 Boyett MR, Lewell BR. A study of the factors responsible for rate-dependent shortening of the action potential in mammalian ventricular muscle. $\mathcal{f}$ Physiol (Lond) 1978; 285:359-80. 
13 Merri M, Moss AJ, Benhorin J, Locati EH, Alberti M, Badilini F. Relation between ventricular repolarization duration and cardiac cycle length during 24-hour Holter recordings: findings in normal patients and patients with recordings: findings in normal patients and patients

14 Merri M, Benhorin J, Alberti M, Locati E, Moss AJ. Electrocardiographic quantitation of ventricular repolarization. Circulation 1989;80:1301-8.

15 Benhorin J, Merri M, Alberti M, Locati E, Hal WJ, Moss AJ. The long QT syndrome: new electrocardiographic characteristics. Circulation 1990;82:521-7.

16 Franz MR, Swerdlow CD, Liem BL, Schaefer J. Cycle length dependence of human action potential duration in vivo. Effects of single extrastimuli, sudden sustained rate acceleration and deceleration, and different steadyrate acceleration and deceleration, and differe

17 Lukas A, Antzelevitch C. Differences in the electrophysiological response of canine ventricular epicardium and endocardium to ischemia: role of the transient outward current. Circulation 1993;88:2903-15.

18 Arnold L, Page J, Attwell D, Cannell M, Eisner DA. The dependence on heart rate of the human ventricular action potential duration. Cardiovasc Res 1982;16: 547-51. 